Yu Dong, Jordan Marshall, Hazim J Haroosh, Soheila Mohammadzadehmoghadam, Dongyan Liu, Xiaowen Qi, Kin-Tak Lau, "Polylactic acid (PLA)/halloysite nanotube (HNT) composite mats: Influence of HNT content and modification", Composites Part A 76 (2015) 28-36.

\title{
Polylactic acid (PLA)/halloysite nanotube (HNT) composite mats: Influence of HNT content and modification
}

Yu Dong a,*, Jordan Marshall ${ }^{\text {a }}$, Hazim J. Haroosh ${ }^{\text {b }}$, Soheila Mohammadzadehmoghadam ${ }^{\mathrm{a}}$, Dongyan Liu ${ }^{\mathrm{c}}$, Xiaowen Qi ${ }^{\mathrm{d}}$, Kin-Tak Lau ${ }^{\mathrm{e}}$

${ }^{a}$ Department of Mechanical Engineering, Curtin University, Perth, WA 6845, Australia

${ }^{b}$ Department of Chemical Engineering, Curtin University, Perth, WA 6845, Australia

${ }^{c}$ Institute of Metal Research, Chinese Academy of Sciences, Shenyang, 110016, China

${ }^{d}$ School of Mechanical Engineering, Yanshan University, Qinhuangdao, 066004, China

${ }^{e}$ Department of Mechanical Engineering, The Hong Kong Polytechnic University, Hung Hom, Kowloon, Hong Kong, China

\begin{abstract}
Polylactic acid (PLA)/halloysite nanotube (HNT) composite mats were successfully fabricated via electrospinning. Composite mats reinforced by both unmodified and modified HNTs with a dispersant BYK-9076 were prepared at the HNT contents of $0,1,5$ and 10 $\mathrm{wt} \% / \mathrm{v}$. The influence of HNT content and modification was investigated comprehensively, based on several characterisation techniques such as scanning electron microscopy (SEM), Xray diffraction (XRD) analysis, mechanical testing, differential scanning calorimetry (DSC), thermogravimetric analysis (TGA) and Fourier transform infrared spectroscopy (FTIR). Typical modified Halpin-Tsai model and modified Halpin-Tsai laminate hybrid model in conventional composite theory were used, which were found difficult to predict the entire experimental data of elastic moduli for PLA/HNT composite mats, possibly arising from the nanosized effect of HNTs and some electrospun PLA nanofibres within composite mats.
\end{abstract}

Keywords: A. Nanoparticles; A: Polymer-matrix composites (PMCs); C: Analytical modelling; E: Electrospinning

* Corresponding author. Tel.: +61 8 92669055; fax: +61 892662681.

E-mail address: Y.Dong@curtin.edu.au (Y. Dong). 


\section{Introduction}

Nanofibrous structures often show exceptionally high specific surface area with the nanoscaled effect to produce high surface energy, surface reactivity, high thermal and electrical conductivity and high strength for fabricated materials [1]. Electrospinning is regarded as one of cheapest and most straightforward material-processing techniques to produce continuous nanofibres with fibre diameters generally ranging from a few nanometres to less than $1 \mu \mathrm{m}$. Its fundamental principle lies in the action of electrostatic forces to overcome the surface tension of polymer/composite solutions so that a charged fluid jet from solution droplets can be further elongated into fibrous structures in an applied high electrical field. With the evaporation of solvents during electrospinning, fibrous structures are collected onto a ground collector or rotating mandrel to form non-woven mats with very large surfaceto-volume ratios. Electrospun fibre mats are widely used in the fields of tissue engineering [2], wound healing [3], drug delivery [4-6], electronics [7] and air filtration [8].

Electrospun nanocomposites are of great concern since they can be simply generated through the addition of nanofillers into a polymer solution, thus resulting in a nanocomposite fibre membrane/mat. Researchers have studied different types of organic or inorganic nanofillers used in electrospinning, which comprise carbon nanotubes (CNTs) [9], nanoclays [10], HNTs [11-15] as well as carbon black nanoparticles [16]. In particular, dissimilar to popular platelet-like montmorillonite (MMT) clays, HNTs have been less extensively researched, which, however, show the great potential to replace CNTs with hollow tubular structures due to their unique chemical properties, abundant availability as well as costeffectiveness. HNTs are a typical aluminosilicate in the kaolinite family [17]. The diameter of HNTs can be ranging from 100 to $300 \mathrm{~nm}$ with an approximate length of $1-3 \mu \mathrm{m}$ [15]. Poly (lactic acid) (PLA) is a widely used biopolymer that is synthesised by the condensation of lactic acid or through ring opening polymerisation of lactide as the diester of lactic acid [18]. 
PLA is generally extracted from natural plants or crops such as corn with good biocompatibility, biodegradability, mechanical properties, easy processibility and light weight for medical and automotive applications [19-21]. Electrospun PLA/HNT composite mats become excellent material media, particularly for tissue scaffolding and effective drug delivery. For instance, HNTs entrap different active agents or enzymes such as drugs, proteins and marine biocides either in their inner lumen or within spaces of aluminosilicate shells $[22,23]$. Furthermore, the incorporation of nanofillers such as HNTs can compensate for typical drawbacks of PLA like poor barrier properties, low thermal stability and limited toughness [24]. The other noteworthy point is that in a PLA/HNT nanocomposite system, HNTs are capable of resisting the harmful PLA degradation products to local tissues due to their hydroxide groups in the hollow tubular structure [15].

The objective of this study is to investigate the effects of HNT content and modification on fibre morphology, mechanical and thermal properties of electrospun PLA/HNT composite mats to further explore the feasibility of HNTs as the potential reinforcements within prepared composite mats.

\section{Material fabrication}

PLA 3051D pellets (molecular weight $\mathrm{MW}=93500 \mathrm{~g} / \mathrm{mol}$ ) were obtained from NatureWorks, USA, and chloroform and methanol solvents were purchased from SigmaAldrich Ltd, Australia. The premium ultrafine HNT powders, as a typical aluminosilicate, were donated by Imerys Tableware Asia Ltd, New Zealand. BYK-9076 dispersant solution, with the composition of alkylammonium salt of a high molecular-weight copolymer, was supplied by Byk-Chemie, Australia to alleviate the HNT sedimentation during electrospinning process with reasonable particle dispersion, as recommended in the previous literature $[11,25]$. 
PLA pellets were initially dissolved in chloroform and methanol (volume ratio: 2:1). They were further mixed at room temperature by a bench top orbital shaking incubator for $3 \mathrm{~h}$ to achieve the desirable $7 \mathrm{wt} \% / \mathrm{v}$ PLA solution. Then unmodified HNT particles were dried at $80^{\circ} \mathrm{C}$ under vacuum for $12 \mathrm{~h}$, and further added to prepare PLA/HNT solutions at the HNT contents of $0,1,5$ and $10 \mathrm{wt} \% / \mathrm{v}$. On the other hand, $20 \mathrm{~g}$ unmodified HNTs were directly added to a $60 \mathrm{ml}$ chloroform and methanol solution (volume ratio: 2:1), and subsequently mixed with a $0.5 \mathrm{ml}$ BYK-9076 dispersant solution. The resulting mixed solution was ultrasonicated for $15 \mathrm{~min}$, and then dried to remove any moisture/solvent from modified HNTs at $160^{\circ} \mathrm{C}$ with the aid of a magnetic stirrer at $400 \mathrm{rpm}$. Modified HNT powders were again mixed separately with initially prepared $7 \mathrm{wt} \% / \mathrm{v}$ PLA solutions to achieve the same HNT contents for comparison.

The electrospinning process was conducted on a NaBond NEU commercial nanofibre electrospinning unit, purchased from NaBond Technologies Co., Ltd, Shenzhen, China. Prepared PLA/HNT solutions were transferred into a $10 \mathrm{ml}$ plastic syringe that was attached to a hypodermic metal needle (inner diameter: $0.56 \mathrm{~mm}$ ) via a $75 \mathrm{~cm}$ syringe extension tubing set with Luer lock connections. The solution-contained syringe was then placed into the Nabond syringe pump, which was automatically operated at a constant feed rate of $3.4 \mathrm{ml} / \mathrm{h}$ to control the fluid flow through the needle tip. The high voltage power supply embedded to the electrospinning unit was set at $20 \mathrm{kV}$. A plate collector covered by aluminium foil was placed with a needle-to-collector distance at $13 \mathrm{~cm}$. Solvent removal was achieved by using the internal fan under the ventilation system. All prepared solutions were ultrasonicated for over 20 min prior to the electrospinning process to acquire the solution homogeneity.

\section{Characterisation methods}

The fibrous structures of non-woven PLA/HNT composite mats, produced with various HNT contents, were investigated by an EVO 40XVP scanning electron microscope (SEM) at 
an accelerating voltage of $10 \mathrm{kV}$. All SEM samples were sputter coated with platinum. With the aid of embedded Zeiss smart SEM software, average fibre diameters and associated standard deviations were determined. These measurements were based on the on-screen measurements of at least 15 fibres from each of scanned SEM images. To identify the embedded HNTs on the surfaces of PLA fibre matrices, material element analysis was also conducted via a Zeiss Neon 40EsB Focussed Ion Beam (FIB) attached to an energy dispersive X-ray spectroscopy (EDS) system at the accelerating voltage of $10 \mathrm{kV}$.

Wide angle X-ray diffraction (XRD) analysis was made using a Bruker D8 ADVANCE diffractometer, Germany to assess the HNT intercalation level of composite mats based on related $d$-spacing values. The $\mathrm{Cu}-\mathrm{K} \alpha$ source (wave length $\lambda=0.1541 \mathrm{~nm}$ ) was operated at 40 $\mathrm{kV}$ and $40 \mathrm{~mA}$. All XRD samples were scanned from $2 \theta=5-40^{\circ}$ at a scan rate of $0.014^{\circ} / \mathrm{s}$.

The tensile properties of composite mat samples in size of $80 \mathrm{~mm} \times 25 \mathrm{~mm}$ were evaluated by a Lloyds EZ50 universal testing machine (load cell: $50 \mathrm{~N}$ ) at the crosshead speed of $40 \mathrm{~mm} / \mathrm{min}$ with a sample gauge length of $50 \mathrm{~mm}$. Over three samples were used for test reproducibility. Tensile modulus and strength data were calculated accordingly, along with reported standard deviations. The thickness of mats was measured using a micrometer at three different mat positions to record the average thickness data in range of 590-830 $\mu \mathrm{m}$.

The DSC thermal analysis was undertaken with a DSC6000 Perkin Elmer, USA in a cryofill liquid nitrogen cooling system to evaluate the melting and crystallisation behaviour of composite mats. About 5-8 mg DSC samples, consisting of PLA fibre mats and PLA/HNT composite mats, were heated from 25 to $200^{\circ} \mathrm{C}$ with a heating rate of $10^{\circ} \mathrm{C} / \mathrm{min}$, and then underwent the isothermal condition at $200{ }^{\circ} \mathrm{C}$ for $5 \mathrm{~min}$ to remove thermal history. Subsequently, samples were cooled from 200 to $25^{\circ} \mathrm{C}$ at the cooling rate of $20^{\circ} \mathrm{C} / \mathrm{min}$. The same heating-cooling scan was repeated for the second time. All the DSC thermograms and associated thermal parameters such as glass transition temperature $\left(T_{g}\right)$, cold crystallisation 
temperature $\left(T_{c c}\right)$ as well as melting temperature $\left(T_{m}\right)$ were determined from the first heating scan. The degree of crystallinity $\left(X_{c}\right)$ was calculated as $[26,27]$

$$
X_{c}(\%)=\frac{\Delta H_{m}-\Delta H_{c c}}{\Delta H_{m}^{0}} \times \frac{100}{1-w_{f}}
$$

Where $\Delta H_{m}$ and $\Delta H_{c c}$ are the heat of fusion and heat of cold crystallisation for PLA fibre matrices within composite mats in this study, respectively. $\Delta H_{m}{ }^{0}$ is a $100 \%$ crystalline PLA material $\left(\Delta H_{m}{ }^{0}=93 \mathrm{~J} / \mathrm{g}[28]\right) \cdot w_{f}$ is the weight fraction of HNTs in mat samples.

Thermogravimetric analysis (TGA) was performed to assess the thermal stability of composite mats by using a TGA/DSC 1 STAR $^{\mathrm{e}}$ System, METTLER TOLEDO, Australia. About $10 \mathrm{mg}$ mat samples were heated from $25^{\circ} \mathrm{C}$ to $800^{\circ} \mathrm{C}$ at a ramp rate of $10^{\circ} \mathrm{C} / \mathrm{min}$ under the flow of argon gas (flow rate: $100 \mathrm{ml} / \mathrm{min}$ ). The weight loss was recorded as the function of temperature.

Fourier transform infrared spectroscopy (FTIR) was employed with a PerkinElmer Spectrum 100 FTIR Spectrometer to detect the interaction level between HNTs and PLA fibre matrices. FTIR spectra were recorded from 4000 to $550 \mathrm{~cm}^{-1}$ with $4 \mathrm{~cm}^{-1}$ resolution based on an attenuated total reflectance (ATR) technique [29].

\section{Mathematical modelling}

The prediction for mechanical properties of electrospun materials can be an important step in the reduction of time and cost for fabricating fibrous structures. The modelling of electrospun nanocomposite fibres in comparison with bulk counterparts becomes far more complex. Their mechanical properties are dependent on the complete structure morphology as well as used nanofillers in terms of filler shape and content. Various investigations have been conducted on the prediction of mechanical properties of nanofibrous structures using finite element analysis and other mathematically derived simulations [30]. The simplest 
mathematical form based on a well-known modified Halpin-Tsai model was presented below by Ramakrishna et al. [31] to predict Young's modulus of clay reinforced electrospun polymer nanofibres:

$$
E_{c}=k\left(\frac{1+\xi \eta v_{f}}{1-\eta v_{f}}\right) E_{m}
$$

and

$$
\eta=\frac{\frac{E_{f}}{E_{m}}-1}{\frac{E_{f}}{E_{m}}+\xi}
$$

Where $E_{c}$ is Young's modulus of filler-reinforced composites, which can be denoted as longitudinal modulus $E_{11}$ and transverse modulus $E_{22}$, respectively. $E_{f}$ and $E_{m}$ are the elastic moduli of fillers and polymer matrices, respectively. $k$ is a proportionality constant [31] that can be determined by the best-fitting of experimental data based on the least square method [32-35]. $v_{f}$ is the volume fraction of fillers and $\xi$ is a shape factor in relation to filler geometry and loading direction. As for tubular fibre-like HNTs, $\xi_{11}=2(L / d)$ and $\xi_{22}=2$ are used for the calculations of longitudinal and transverse elastic moduli $E_{11}$ and $E_{22}$, respectively [36]. $L$ and $d$ are the length and diameter of dispersed HNTs.

The drawback of above-mentioned modified Halpin-Tsai model lies in the assumption of well-aligned inclusions in unidirectional composites. In reality, it is the general case that most composites contain a certain level of filler disorientation. In particular, fibre-like HNTs in composite mats also tend to be dispersed with a certain level of misalignment and random orientation [12]. Thus a mathematical laminate model [36-38] to account for the completely disordered HNTs in all three orthogonal directions can be expressed in the following form:

$$
E_{\text {ran }-3 D}^{H N T s}=E_{c}=0.184 E_{/ /}+0.816 E_{\perp}
$$

Where $E_{/ /}$and $E_{\perp}$ are composite moduli in the parallel and perpendicular directions to the 
major axes of HNTs, respectively. With the combination of equations (2) and (4), a modified Halpin-Tsai laminate hybrid model [36] can be established by using $E_{/ /}=E_{11}$ and $E_{\perp}=E_{22}$ accordingly. Such laminate hybrid model is very useful to predict mechanical properties of polymer nanocomposites with 3D random-oriented nanofillers with the closer formation to real morphological structures [36].

The analytical work based on modified Halpin-Tsai model and modified Halpin-Tsai laminate hybrid model was conducted in comparison with experimental data according to the modelling parameters listed in Table 1.

\section{Results and discussion}

\subsection{Fibre morphology}

The morphology of fibrous structures is presented in Fig. 1, which reveals that most fibres are in randomly oriented non-woven formations. The consistently uniform fibres are more manifested for composite mats reinforced with modified HNTs, especially at HNT contents of 5 and $10 \mathrm{wt} \% / \mathrm{v}$, Figs. $1(\mathrm{~g})$ and (h). The average fibre diameters of composite mats, as illustrated in Fig. 2, are in range of 966-1163 nm as opposed to that of PLA counterparts at $1043 \mathrm{~nm}$. The inclusion of unmodified HNTs appears to moderately increase the fibre diameter of PLA mats. This phenomenon can be attributed to the enhanced solution viscosity due to additional HNTs, which is proven to further induce increased fibre diameters [12]. Nevertheless, the use of dispersant for modified HNTs contrarily decreases the fibre diameter of PLA/modified HNT composite mats. It is implied that better HNT dispersion may be achieved to alleviate the clogging issue, arising from HNT agglomerates during electrospining. Overall, PLA/HNT composite mats consist of a majority of electrospun microfibres with the fibre diameter of nearly over $1 \mu \mathrm{m}$ regardless of HNT contents. The narrow distribution bands of fibre size also signify that the average fibre diameter is not 
significantly altered by different HNT contents, which is in good accordance with previous results from electrospun polycaprolactone (PCL)/MMT composites [10].

EDS spectra to identify compositions of fibrous structures are demonstrated in Fig. 3. Apparently, carbon and oxygen elements can be assigned to organic components of PLA biopolymer; whereas aluminium and silicon elements are clearly indicative of existing HNTs with their chemical structure of $\left(\mathrm{Al}_{2} \mathrm{Si}_{2} \mathrm{O}_{5}(\mathrm{OH})_{4} \cdot \mathrm{nH}_{2} \mathrm{O}\right)$. The additional platinum is most likely due to the sputter coating effect during the SEM sample preparation. It is evident that HNTs are well embedded on outer surfaces of individual PLA fibres to induce the good interfacial interactions. Furthermore, surface roughness of PLA fibres on composite mats is inevitably more pronounced due to the HNT dispersion.

\subsection{XRD data}

The effect of HNT intercalation level was detected from XRD patterns in Fig. 4. Three typical XRD peaks for as-received HNT powders appear at $2 \theta=12.09,19.90$ and $24.85^{\circ}$ in accord with reflection planes (001), (020), (110) and (002) with $d$-spacing values of 0.732 , 0.446 and $0.358 \mathrm{~nm}[11,14,40]$, respectively. The hydration state of HNTs is based upon the presence of interlayer water in HNTs, and can be characterised by a clear sign of $10 \AA$ reflection peak for hydrated HNTs and $7 \AA$ reflection peak for dehydrated HNTs in XRD patterns [41]. Because of missing $10 \AA$ reflection peak $\left(2 \theta=8.76^{\circ}\right)$, as-received $\mathrm{HNT}$ powders used in this study are fully dehydrated, which are also known as $7 \AA$-halloysite [11, 42]. The presence of (002) reflection peak at $2 \theta=24.85^{\circ}$ also confirms such a dehydrated state of HNTs [41, 42]. As for PLA/unmodified HNT composite mats, the intercalation of PLA molecules into the interlayers of HNT hollow tubular structure does not take place in that $d$-spacing values for their weak (001) peaks almost remain unchanged at $0.716,0.732$ and $0.725 \mathrm{~nm}$ with the HNT contents of 1,5 and $10 \mathrm{wt} \% / \mathrm{v}$, respectively; whereas (020), (110) and (002) peaks become invisible at all. This finding is in good agreement with the previous 
work on both bulk solid material of PLA/HNT nanocomposites [40] as well as electrospun PLA/HNT composite mats [11]. In particular, the formation of elongated PLA molecular chains by electrospinning can further hinder the penetration into rolled HNT tubular sheets. Additionally, strong hydrogen bonding [40] between HNT interlayers can be the other reason to prevent the intercalation effect, which is not the case for platelet-like MMT clays that can be easily inserted with polymeric molecules by mechanical shear stress or chemical processing. Hence, it may be implied that a majority of PLA molecules tend to attach to the outer surfaces of HNTs as evidenced in Fig. 3. On the other hand, reflection peaks of all PLA/modified HNT composite mats in relation to XRD patterns of HNTs completely disappeared, which indicates that some crystal structures of HNTs may be potentially destroyed, resulting in a sheet-like shape [43, 44]. More interestingly, a weak and board scattering reflection was detected at approximately $2 \theta=16.8^{\circ}$ for neat PLA mats. Similar reflection peaks were also observed for all PLA/HNT composite mats. This phenomenon signifies that both PLA mats and PLA components within composite mats exhibit a predominant amorphous nature with minor PLA crystalline structures. Finally, the complete disappearance of (020), (110) and (002) peaks for PLA/HNT composite mats may also be attributed to the dominant dilution effect [45]. It is also the case for dilution effect in which reflection peaks of HNTs may be superimposed to the PLA peak in $2 \theta$ range of $10-20^{\circ}$, especially for PLA/10 wt\%/v HNTs. Such composite mats, due to their fibrous structure with high porosity, inevitably possess much smaller amounts of HNTs than bulk solid PLA/HNT nanocomposites of the same size. Consequently, insufficient XRD beam diffraction can happen for composite mats leading to the peak disappearance as opposed to distinct and sharp XRD peaks observed in their solid nanocomposite counterparts [40]. 


\subsection{Tensile properties}

Tensile properties of PLA/HNT composite mats as well as their typical stress-strain curves are presented in Figs. 5 and 6, respectively. Consistently high tensile moduli and strengths of all composite mats over those of PLA counterparts are indicative of significant reinforcement effect of HNTs, as demonstrated in Figs. 5(a) and (b). Moreover, modified HNTs have been shown to prevalently contribute to a further enhancement of tensile properties as opposed to unmodified HNTs, which is the typical case in Fig. 6. In particular, the maximum increases of tensile modulus and strength by 401 and $134 \%$ are obtained for PLA/modified HNT composite mats at the HNT contents of $10 \mathrm{wt} \% / \mathrm{v}$ and $1 \mathrm{wt} \% / \mathrm{v}$, respectively. Such remarkable improvement may directly arise from better HNT dispersion when using BYK dispersant. However, the inclusion of $10 \mathrm{wt} \% / \mathrm{v}$ unmodified HNTs within composite mats apparently gives rise to an abrupt drop of tensile modulus comparable to that of PLA. This detrimental effect is probably ascribed to a certain extent of unmodified HNT agglomeration at high content levels. In general, the increase of the rigidity (i.e. elastic modulus) of a composite material is well known when rigid particles such as HNTs are incorporated into polymer matrices $[31,39]$. The improvement of tensile strength is generally associated with the good interfacial bonding for the effective stress transfer from PLA fibre matrices to HNT particles, which is proven for both PLA/unmodified HNT and PLA/modified HNT composite mats with the aid of SEM micrographs and associated EDS spectra in Fig. 3.

\subsection{DSC measurements}

DSC thermograms of PLA fibre mats and PLA/HNT composite mats are depicted in Fig. 7, along with associated thermal parameters listed in Table 2 . It can be found that $T_{g}$ slightly decreases from $54.9^{\circ} \mathrm{C}$ for PLA mats to $50-52^{\circ} \mathrm{C}$ for composite counterparts. It may be due to the reduction of entanglements and interactions for PLA polymer chains through HNT inclusions, thus resulting in a plasticisation effect to promote the motion of polymer chains 
$[46,47]$. However, this effect is quite trivial since the increase of HNT content as well as HNT modification cause little alterations of $T_{g}$. The peaks of cold crystallisation for PLA/HNT composite mats are shifted to lower temperature levels, given by $T_{c c}$ values in range of $79.4-81.6^{\circ} \mathrm{C}$ as opposed to $84.3^{\circ} \mathrm{C}$ for PLA mats. Such material behaviour is a wellknown nucleating effect of HNTs to accelerate the cold crystallisation process of PLA fibre matrices, which is in good accordance with previous studies [11, 14, 15, 40,46]. On the other hand, $T_{m}$ values of composite mats are consistently lower than that for PLA counterparts. This finding can be explained by incomplete crystalline structures formed by the HNT heterogeneous nucleation with thinner and/or less perfect crystalline lamella $[39,47]$. As a result, composite mats tend to have lower melting points than that of PLA mats with more complete crystalline structures. The change of $X_{c}$ becomes less pronounced in range from $10.5-13.4 \%$ as compared with $13.2 \%$ for PLA mats, which is also indicative of prevalent amorphous structures of PLA fibre mats and PLA/HNT composite mats in aforementioned XRD results.

\subsection{Thermal stability}

The TGA results to characterise thermal stability of PLA fibre mats, PLA/HNT composite mats, as-received HNTs and HNTs/BYK are demonstrated in Fig. 8. The major parameters including $T_{5 \%}, T_{50 \%}, T_{95 \%}$ as well as $T_{d 1}, T_{d 2}$ and $T_{d 3}$ are listed in Table 3. $T_{5 \%}, T_{50 \%}, T_{95 \%}$ refer to decomposition temperatures at 5,50 and 95\% mass loss taking place in TGA curves, respectively. $T_{d 1}, T_{d 2}$ and $T_{d 3}$ are corresponding temperatures of maximum degradation rate for degradation peaks 1, 2 and 3 in derivative thermogravimetric (DTG) curves. As-received HNTs induce relatively high $T_{5} \%$ and $T_{d 3}$ above $430{ }^{\circ} \mathrm{C}$ compared to HNTs/BYK, which is expected due to the better thermal resistance of raw HNTs as 1:1 phyllosilicate with tubular structures. Irrespective of HNT modification, onset temperatures at 5\% mass loss for PLA/HNT composite mats become much lower in range from $242-249^{\circ} \mathrm{C}$ relative to $284{ }^{\circ} \mathrm{C}$ 
for PLA counterparts. A similar decreasing trend is also manifested at 50\% mass loss while increasing the HNT content appears to alleviate the reduction level of $T_{50 \%}$ for both unmodified and modified HNT composite mats. The decrease of thermal stability at the above-mentioned two onset temperature levels is ascribed to the catalytic role of HNTs on the PLA pyrolysis with the existence of Si-OH and Al-OH acid sites on HNT external surfaces [48, 49]. However, when the mass loss reaches 95\%, $T_{95 \%}$ values for composite mats conversely have monotonic increases with increasing the HNT content up to maximum 402.9 and $420.8{ }^{\circ} \mathrm{C}$ for $10 \mathrm{wt} \% \mathrm{HNT}$ and modified HNT inclusions, respectively $\left(T_{95 \%}=370.0^{\circ} \mathrm{C}\right.$ for PLA mats). HNT modification results in relatively high $T_{95} \%$ values for composite mats except for $5 \mathrm{wt} \% / \mathrm{v}$ HNT inclusions. All composite mats possess three degradation steps with three distinct maxima as opposed to one degradation step for PLA mats, Fig. 8(b). The main maxima indicators $T_{d 2}$ and $T_{d 3}$ to reflect the temperatures of maximum degradation rate also reveal the increasing tendencies with increasing HNT contents, which is more pronounced for HNT modified composite mats. In particular, $T_{d 3}$ values in range from $354.7-362.7^{\circ} \mathrm{C}$ for composite mats are consistently higher than that of PLA mats at $354.1{ }^{\circ} \mathrm{C}$. As mentioned elsewhere $[47,50]$, hollow tubular structure of HNTs may promote the entrapment of volatile degradation products inside lumens, and thus delay the mass transfer and increase the thermal stability of PLA fibre matrices. Modified HNTs may also be better dispersed with higher randomness of lumen ends to achieve more efficient entrapment phenomenon. It is still uncertain about the appearance of first and second degradation steps, as characterised by $T_{d 1}$ in the temperature range of $280.8-294.5{ }^{\circ} \mathrm{C}$ and $T_{d 2}$ from 305.46 to $311.22{ }^{\circ} \mathrm{C}$ for all PLA/HNT composite mats. However, it may be associated with the iron impurity of asreceived $\mathrm{HNTs}$ such as $\mathrm{Fe}_{2} \mathrm{O}_{3}$ [50], which is in good accordance with TGA results of polyurethane / $\mathrm{Fe}_{2} \mathrm{O}_{3}$ nanocomposites [51]. 


\subsection{FTIR spectra}

FTIR spectra of PLA mats, HNT powders and PLA/HNT composite mats are demonstrated in Fig. 9. Neat PLA mats exhibit carbonyl stretching $\mathrm{C}=\mathrm{O}$ bands at $1751 \mathrm{~cm}^{-1}$. HNT powders reveal two intense bands at 3621 and $3694 \mathrm{~cm}^{-1}$ to represent the $\mathrm{O}-\mathrm{H}$ group vibration. The other relevant peaks at 1005 and $910 \mathrm{~cm}^{-1}$ are associated with the stretching of $\mathrm{Si}-\mathrm{O}$ and $\mathrm{Al}-\mathrm{OH}$ groups, respectively. The single PLA band at $1266 \mathrm{~cm}^{-1}$ has been sharpened when embedded with HNTs and HNTs/BYK to form PLA/HNT composite mats. It is suggested that a reasonable contribution of HNT bands with wave numbers of 1117, 1027 and $1005 \mathrm{~cm}^{-1}$ is due to the stretching of $\mathrm{Si}-\mathrm{O}$. Furthermore, vibration bands of surface hydroxyl groups and O-H groups, originally detected in HNTs' spectrum at 3621 and 3694 $\mathrm{cm}^{-1}$, become very weak for most PLA/HNT composite mats. A new strong absorbance peak takes place at $1721 \mathrm{~cm}^{-1}$ for PLA/HNT composite mats, indicating the clear interaction between HNTs and $\mathrm{C}=\mathrm{O}$ carbonyl group. However, the effect of BYK dispersant on the change of bonds for composite mats appears to be quite insignificant.

\section{Mathematical modelling of electrospun composite mats}

The prediction of tensile moduli of electrospun composite mats is illustrated in Fig. 10, which is based on two mathematical models including modified Halpin-Tsai model and modified Halpin-Tsai laminate hybrid model. For simplicity, the elastic modulus of electrospun PLA fibre matrices is assumed to be constant in Table 1 since the variation of average fibre diameter is not significant in terms of HNT contents irrespective of HNT modification. This hypothesis is assessed from the criterion of determined matrix modulus as a function of fibre diameter in [31]. By fitting individual experimental data, the $k$ values are detected in range from 1.11 to 2.36. For unmodified HNT inclusions, modified Halpin-Tsai laminate hybrid model is in better agreement with experimental data of composite mats, 
especially for modelling the modulus drop at the high HNT content of $10 \mathrm{wt} \% / \mathrm{v}$. Similarly, the same model fits better for composite mats with modified HNT inclusions, particularly in excellent accordance with those data at 1 and $5 \mathrm{wt} \% / \mathrm{v}$. This finding may imply that HNT dispersion tends to be more randomly oriented within PLA fibre matrices in 3-D dimensions. Unfortunately, both models fail to predict the entire trends of experimental modulus data, which suggests the size effect of HNTs and electrospun PLA fibres partially at nanoscaled level significantly influence mechanical properties of their composite mats, thus resulting in the invalidity of conventional composite models.

\section{Conclusions}

PLA/HNT composite mats were successfully achieved by electrospinning in order to understand the influence of HNT contents and modification within composite fibrous structures. Uniform fibre morphology with average fibre diameters around $1 \mu \mathrm{m}$ was found mainly in composite mats reinforced with modified HNTs at 5 and $10 \mathrm{wt} \% / \mathrm{v}$. XRD results demonstrate that no HNT intercalation effect occurs and PLA molecules tend to attach to outer surfaces of HNTs. HNT modification is also confirmed to benefit the significant enhancements of tensile moduli and strengths for composite mats. The addition of HNTs and their unique tubular structures lead to the accelerated cold crystallisation of PLA fibre matrices as well as the improved thermal stability of composite mats, respectively. HNTs and carbonyl group appear to interact very closely, but the use of BYK dispersant has little impact on the bond groups. Halpin-Tsai laminate hybrid model has the capacity to better predict experimental data for tensile moduli of composite mats than modified Halpin-Tsai model at certain HNT contents. However, neither of models offers the consistent fitting with their overall experimental modulus trends.

\section{References}

[1] He JH, Liu Y, Mo LF, Wan YQ, Xu L. Electrospun nanofibres and their applications. Shawbury, UK: Smithers Rapra Technology; 2008. 
[2] Dahlin R, Kasper K, Mikos A. Polymeric nanofibers in tissue engineering. Tissue Eng Part B 2011; 17: 349-64.

[3] Jung SY, Park KE, Lee SJ, Min BM, Park WH. Biomimetic nanofibrous scaffolds: preparation and characterization of chitin/silk fibroin blend nanofibers. J Biol Macromolecules 2006; 38: 165-73.

[4] Bian X, Zeng J, Xu X, Chen X, Liang Q, Yang L, Jing X. Biodegradable electrospun fibers for drug delivery. J Control Release 2003; 92: 227-31.

[5] Haroosh HJ, Dong Y, Lau KT. Tetracycline hydrochloride (TCH) loaded drug carrier based on PLA: PCL nanofibre mats: experimental characterisation and release kinetics modelling. J Mater Sci 2014; 49: 6270-81.

[6] Haroosh HJ, Dong Y, Ingram GD. Synthesis, morphological structures and material characterization of electrospun PLA: PCL/magnetic nanoparticle composites for drug delivery. J Polym Sci Part B 2013; 51: 1607-17.

[7] Bishop A, Gouma P. Leuco-emeraldine based polyaniline-poly-vinyl-pyrrolidone electrospun composites and bio-composites: a preliminary study of sensing behaviour. Rev Adv Mater Sci 2005; 10: 209-14.

[8] Graham K, Ouyang M, Raether T, Grafe T, McDonald B, Knauf P. polymeric nanofibers in air filtration applications. Proceedings of the Fifteen Annual Technical Conferences \& Expo of the American Filtration \& Separations Society, Galveston, Texas; 2002.

[9] Ajji A, Mazinani S, Dubois C. Morphology, structure and properties of conductive PS/CNT nanocomposite electrospun mat. Polymer 2009; 50: 3329-42.

[10] Marras SI, Kladi KP, Tsivintzelis I, Zuburtikudis I, Panayiotou C. Biodegradable polymer nanocomposites: the role of nanoclays on the thermomechanical characteristics and the electrospun fibrous structure. Acta Biomater 2008; 4: 756-65.

[11] Dong Y, Bickford T, Haroosh HJ, Lau KT, Takagi H. Multi-response analysis in the material characterisation of electrospun poly (lactic acid)/ halloysite nanotube composite fibres based on Taguchi design of experiments: fibre diameter, nonintercalation and nucleation effects. Appl Phys A Mater Sci Process 2013; 112: 747-57.

[12] Haroosh HJ, Dong Y, Chaudhary DS, Ingram GD, Yusa S. electrospun PLA: PCL composites embedded with unmodified and 3-Aminopropyltriethoxysilane (ASP) modified halloysite nanotubes (HNT). Appl Phys A Mater Sci Process 2013; 110: 433-42.

[13] Haroosh HJ, Chaudhary DS, Dong Y. Electrospun PLA/PCL fibers with tubular nanoclay: morphological and structural analysis. Appl Polym Sci 2012; 124: 3930-9. 
[14] Dong Y, Chaudhary D, Haroosh H, Bickford T. Development and characterisation of novel electrospun polylactic acid/tubular clay nanocomposites. J Mater Sci 2011; 46: 6148-53.

[15] Touny A, Lawrence J, Jones A, Bhaduri S. Effect of electrospinning parameters on the characterization of PLA/HNT nanocomposite fibers. J Mater Res 2010; 25: 857-65.

[16] Chuangchote S, Sirivat A, Supaphol P. Mechanical and electro-rheological properties of electrospun poly(vinyl alcohol) nanofibre mats filled with carbon black nanoparticles. Nanotechnology 2007; 18: 145705.

[17] Bailly C, Leciuvet B, Horion J, D’Haese C, Nysten B. Elastic modulus of halloysite nanotubes. Nanotechnology 2013; 24:105704.

[18] Li HL, Zhao YQ, Lau KT, Cheung HY. Chicken feather fiber/poly(lactic acid) green composites: mechanical, thermal and biodegradable properties. In: Willems, F, Moens, P, editors. Green Composites: Properties, Design and Life Cycle Assessment. New York: Nova Science Publisher, 2010. p. 119-39.

[19] Vainionpää S, Rokkanen P, Törmälä P. Surgical applications of biodegradable polymers in human tissues. Prog Polym Sci 1989; 14: 679-716.

[20] Manninen MJ, Päivärinta U, Pätiälä H, Rokkanen P, Taurio R, Tamminmäki M, Törmälä P. Shear strength of cancellous bone after osteotomy fixed with absorbable selfreinforced polyglycolic acid and poly- $L$-lactic acid rods. J Mater Sci-Mater Med 1992; 3: $245-51$.

[21] Ino T, Kageyama Y, Koizumi J, Mori T. Applied investigation of bioplastics. In: Proceedings of JSAE Annual Congress. Yokohama, May, 2003. p. 11-3.

[22] Lvov YM, Shchukin DG, Möhwald H, Price RR. Halloysite clay nanotubes for controlled release of protective agents. ACS Nano 2008; 2:814-20.

[23] Price RR, Gaber BP, Lvov Y. In-vitro release characteristics of tetracycline HCl, khellin and nicotinamide adenine dineculeotide from halloysite; a cyclindrical mineral. $\mathbf{J}$ Microencap 2001; 18: 713-22.

[24] Russo P, Cammarano S, Bilotti E, Peijs T, Cerruti P, Acierno D. Physical properties of poly lactic acid/clay nanocomposite films: effect of filler content and annealing treatment. J Appl Polym Sci 2014; 131: 39798

[25] Zhao Y, Duan Y, Yuan L, Guan F. The dispersion of SWCNTs treated by dispersing agents in glass fiber reinforced polymer composites. Compos Sci Technol 2009; 69: 2115-8. 
[26] Shi Q, Zhou C, Yue Y, Guo W, Wu Y, Wu Q. Mechanical properties and in vitro degradation of electrospun bio-nanocomposite mats from PLA and cellulose nanocrystals. Carbohydr Polym 2012; 90: 301-8.

[27] Zhou H, Green TB, Joo YL. The thermal effects on electrospinning of polylactic acid melts. Polymer 2006; 47: 7497-505.

[28] Riga A, Zhang J, Collis J. Characterization of drawn and undrawn poly-L-lactide films by differential scanning calorimetry. J Therm Ana Calorim 2004; 75: 257-68.

[29] Chittur KK. FTIR/ATR for protein absorption to biomaterial surfaces. Biomaterials 1998; 19: 357-69.

[30] Stylianopoulos T, Bashur C, Goldstein A, Guelcher S, Barocas V. Computational prediction of the tensile properties of electrospun fiber meshes: effect of fiber diameter and fiber orientation. J Mech Behav Biomed Mater 2008; 1: 326-35.

[31] Ramakrishna S, Lim TC, Inai R, Fujihara K. Modified Halpin-Tsai equation for clayreinforced polymer nanofiber. Mech Adv Mater Struct 2006; 13: 77-81.

[32] Marquardt DW. An algorithm for least-squares estimation of nonlinear parameters. J Soc Indust Appl Math 1963; 11: 431-41.

[33] Dong Y, Lin RJT, Bhattacharyya D. Determination of critical material parameters for numerical simulation of acrylic sheet forming. J Mater Sci 2005; 40: 399-410.

[34] Dong Y, Chaudhary D, Ploumis C, Lau KT. Correlation of mechanical performance and morphological structures of epoxy micro/nanoparticulate composites. Compos Part A: Appl Sci Manuf 2011; 42:1483-92.

[35] Dong Y, Ghataura A, Takagi H, Haroosh HJ, Nakagaito AN, Lau KT. Polylactic acid (PLA) biocomposites reinforced with coir fibres: evaluation of mechanical performance and multifunctional properties. Compos Part A: Appl Sci Manuf 2014; 63: 76-84.

[36] Dong Y, Bhattacharyya D. Mapping the real micro/nanostructures for the prediction of elastic moduli of polypropylene/clay nanocomposites. Polymer 2010; 51: 816-24.

[37] van Es M, Xiqiao F, van Turnhout J, van der Giessen E. Comparing polymer-clay nanocomposites with conventional composites using composite modeling. In: AlMalaika, S, Golovoy, A, Wilkie, CA, editors. Specialty Polymer Additives: Principles and Applications. Oxford, UK: Blackwell Science Publishers, 2001. p. 391-414.

[38] Hull D, Clyne TW. An introduction to composite materials. New York: Cambridge University Press; 1996.

[39] Lecouvet B, Horion J, D’Haese C, Bailly C, Nysten B. Elastic modulus of halloysite nanotubes. Nanotechnology 2013; 24: 105704. 
[40] Liu M, Zhang Y, Zhou C. Nanocomposites of halloysite and polylactide. Appl Clay Sci 2013; 75-76: 52-9.

[41] Levis SR, Deasy PB. Characterisation of halloysite for use as a microtubular drug delivery system. Int J Pharm 2002; 243: 125-34.

[42] Soheilmoghaddam M, Wahit MU, Mahmoudian S, Hanid NA. Regenerated cellulose/halloysite nanotube nanocomposite films prepared with an ionic liquid. Mater Chem Phys 2013; 141: 936-43.

[43] Liu Y, Cai Q, Li H, Zhang J. Fabrication and characterization of mesoporous carbon nanosheets using halloysite nanotubes and polypyrrole via a template-like method. $\mathbf{J}$ Appl Polym Sci 2013; 128: 517-22.

[44] Wang A, Kang F, Huang Z, Guo Z, Chuan X. Synthesis of mesoporous carbon nanosheets using tubular halloysite. Microporous Mesoporous Mater 2008; 108: 318-24.

[45] Carli LN, Crespo JS, Mauler RS. PHBV nanocomposites based on organomodified montmorillonite and halloysite: the effect of clay type on the morphology and thermal and mechanical properties. Compos Part A: Appli Sci Manuf 2011; 42:1601-8.

[46] Wu W, Cao X, Zhang Y, He G. Polylactide/halloysite nanotube nanocomposites: thermal, mechanical properties, and foaming processing. Appl Polym Sci 2013; 130: 443-52.

[47] Lecouvet B, Gutierrez JG, Sclavons M, Baily C. Structure-property relationships in polyamide 12/halloysite nanotube nanocomposites. Polym Degrad Stabil 2011; 96: 22635.

[48] Stoclet G, Sclavons M, Lecouvet B, Devaux J, Van Velthem P, Boborodea A, Bourbigot S, Sallem-Idrissi. Elaboration of poly(lactic acid)/halloysite nanocomposites by means of water assisted extrusion: structure, mechanical properties and fire performance. RSC Adv 2014; 4: 57553-63.

[49] Kopinke FD, Remmler M, Mackenzie K, Möder M, Wachsen O. Thermal decomposition of biodegradable polyesters - Poly(lactic acid). Polym Degrad Stabil 1996; 53: 329-42.

[50] Du M, Guo B, Jia D. Thermal stability and flame retardant effects of halloysite nanotubes on poly(propylene). Eur Polym J 2006; 42:1362-9.

[51] Guo Z, Lee SE, Kim H, Park S, Hahn HT, Karki AB, Young DP. Fabrication, characterization and microwave properties of polyurethane nanocomposites reinforced with iron oxide and barium titanate nanoparticle. Acta Mater 2009; 57: 267-77. 


\section{List of figures}

Fig. 1. SEM images of electrospun composite mats at different HNT contents: (a) $0 \mathrm{wt} \% / \mathrm{v}$ (i.e. neat PLA), (b) unmodified $1 \mathrm{wt} \% / \mathrm{v}$ HNTs, (c) unmodified $5 \mathrm{wt} \% / \mathrm{v}$ HNTs, (d) unmodified $10 \mathrm{wt} \% / \mathrm{v}$ HNTs, (e) modified $1 \mathrm{wt} \% / \mathrm{v}$ HNTs, (f) modified $3 \mathrm{wt} \% / \mathrm{v}$ HNTs, (g) modified $5 \mathrm{wt} \% / \mathrm{v}$ HNTs, (h) modified $10 \mathrm{wt} \% / \mathrm{v}$ HNTs. All the scale bars represent $10 \mu \mathrm{m}$.

Fig. 2. Effect of HNT contents on average fibre diameters for PLA/unmodified HNT and PLA/modified HNT composite mats.

Fig. 3. EDS spectra of PLA/HNT composite mats: (a) $5 \mathrm{wt} \% / \mathrm{v}$ unmodified HNTs, (b) 5 wt $\% / \mathrm{v}$ modified HNTs, (c) $10 \mathrm{wt} \% / \mathrm{v}$ unmodified HNTs and (d) $10 \mathrm{wt} \%$ modified HNTs. Circles within built-in EDS images indicate embedded HNTs.

Fig. 4. XRD patterns of PLA/HNT composite mats and as-received HNT powders.

Fig. 5. Tensile properties of PLA/unmodified HNT and PLA/modified HNT composite mats: (a) tensile modulus and (b) tensile strength.

Fig. 6. Typical stress-strain curves of PLA mats and PLA/HNT composite mats.

Fig. 7. DSC thermograms of PLA mats and PLA/HNT composite mats.

Fig. 8. TGA thermograms of PLA mats, PLA/HNT composite mats, as-received HNTs and HNTs/BYK: (a) TGA curves and (b) DTG curves.

Fig. 9. FTIR spectra of PLA mats, as-received HNTs and PLA/HNT composite mats.

Fig. 10. Prediction of tensile moduli of PLA/HNT composite mats using modified HalpinTsai model and modified Halpin-Tsai laminate hybrid model. 

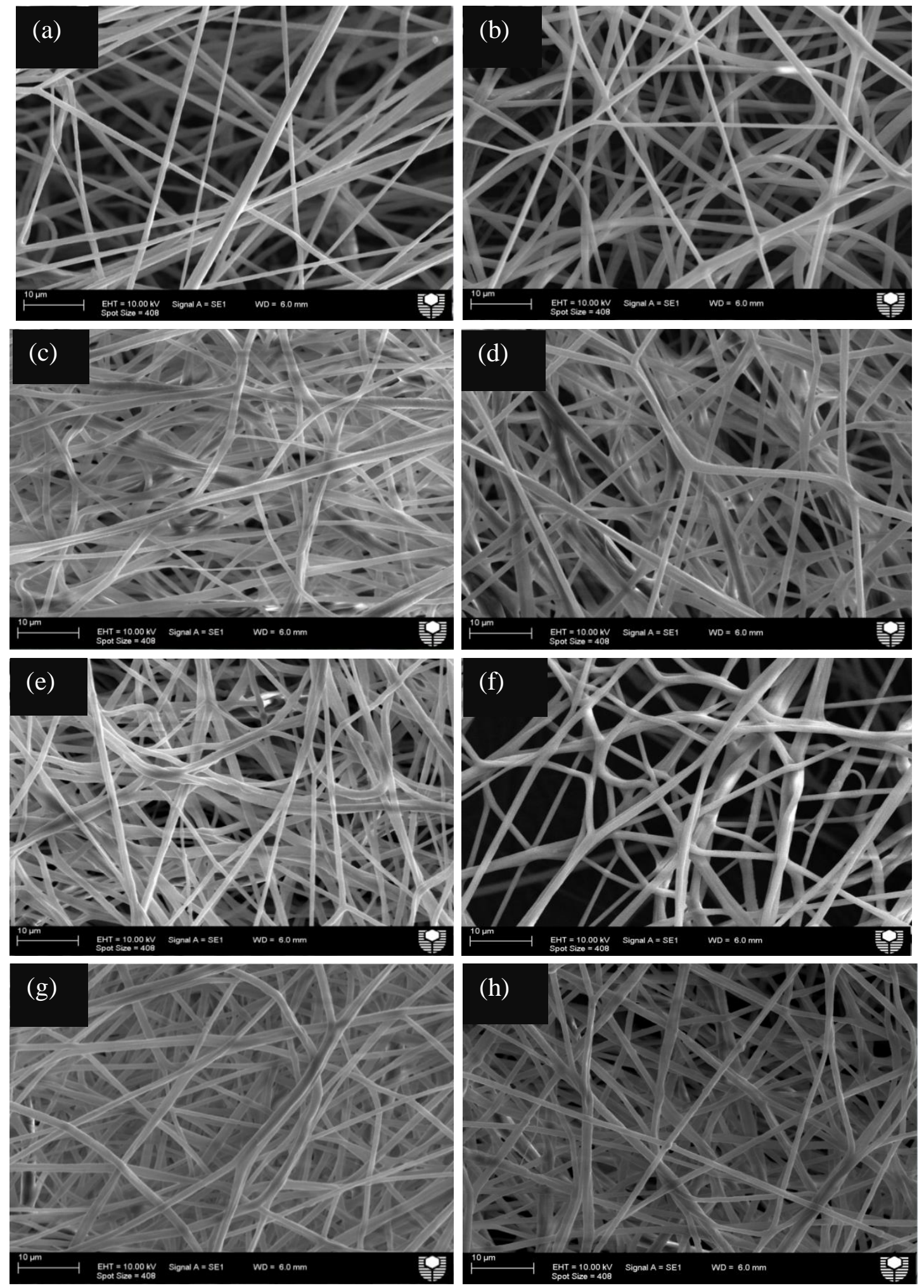

Fig. 1. 


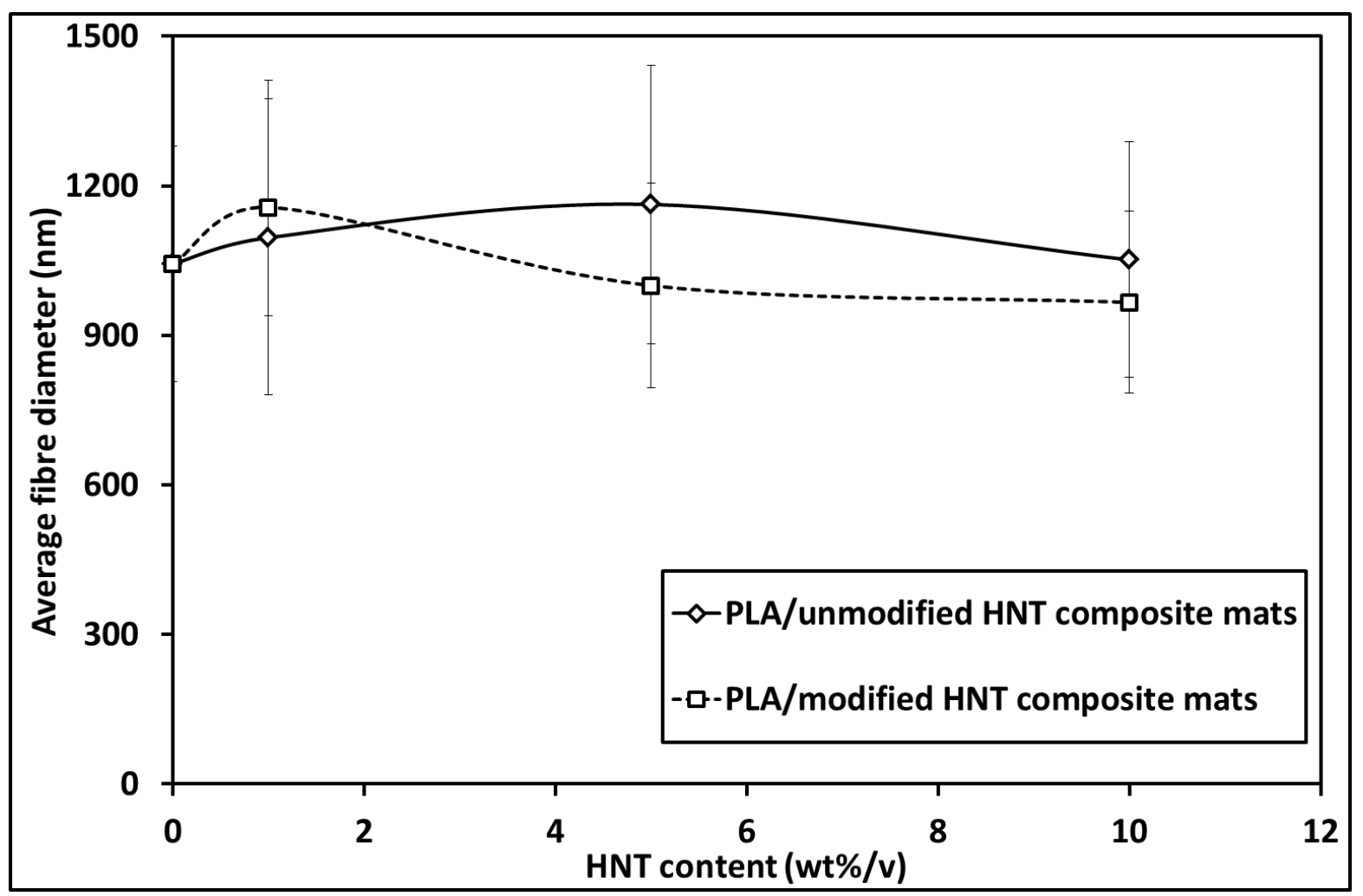

Fig. 2. 

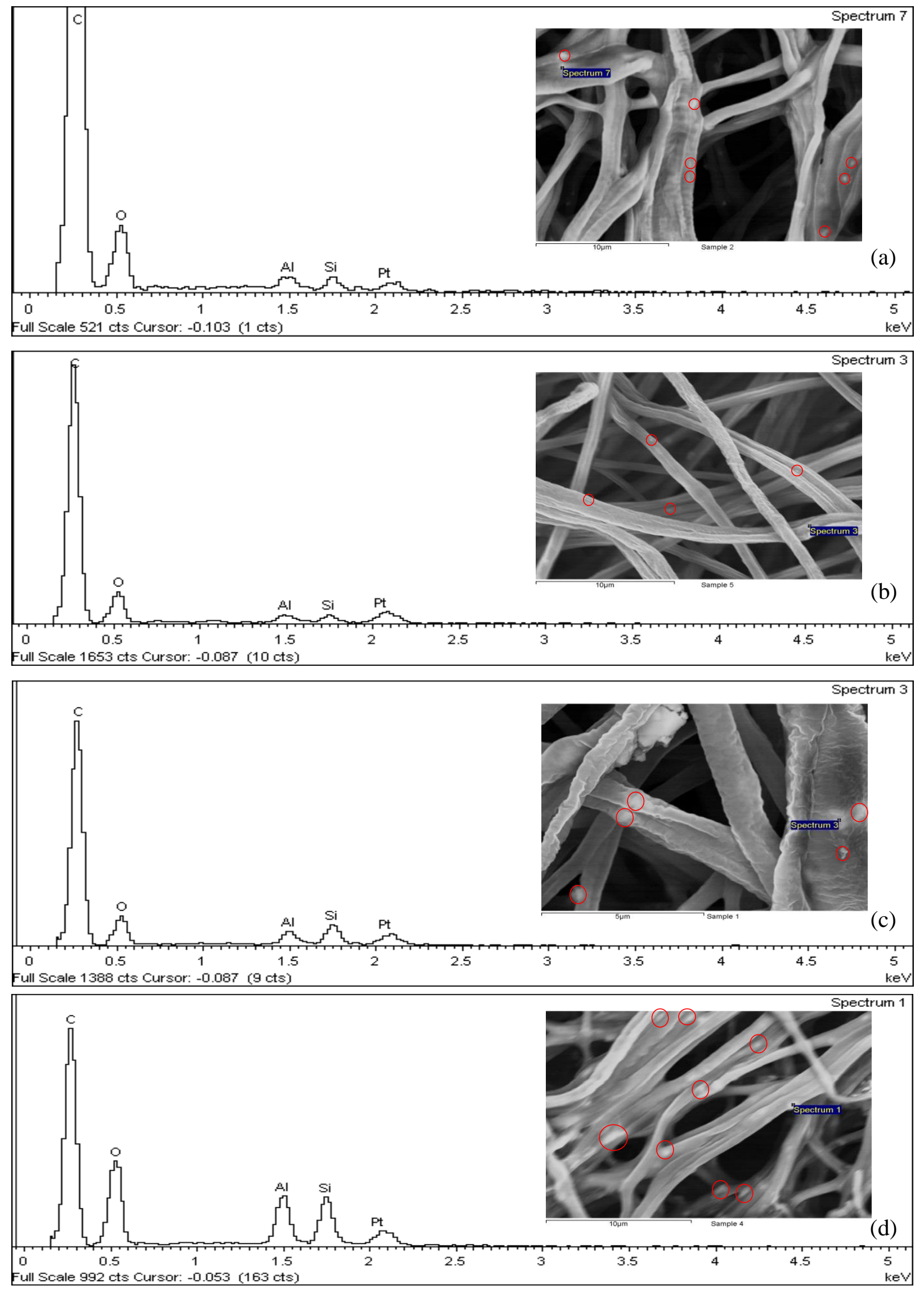

Fig. 3. 


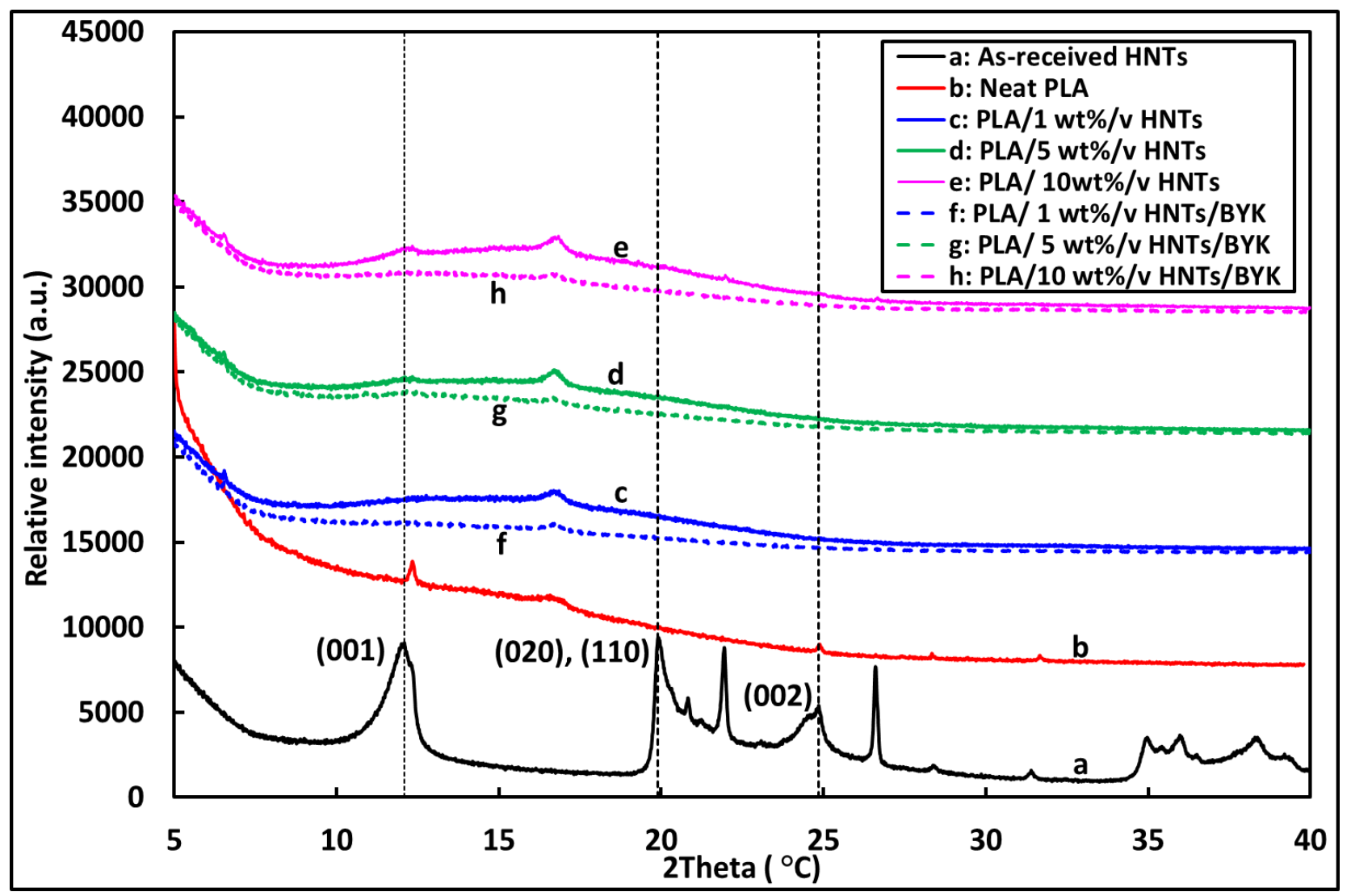

Fig. 4. 

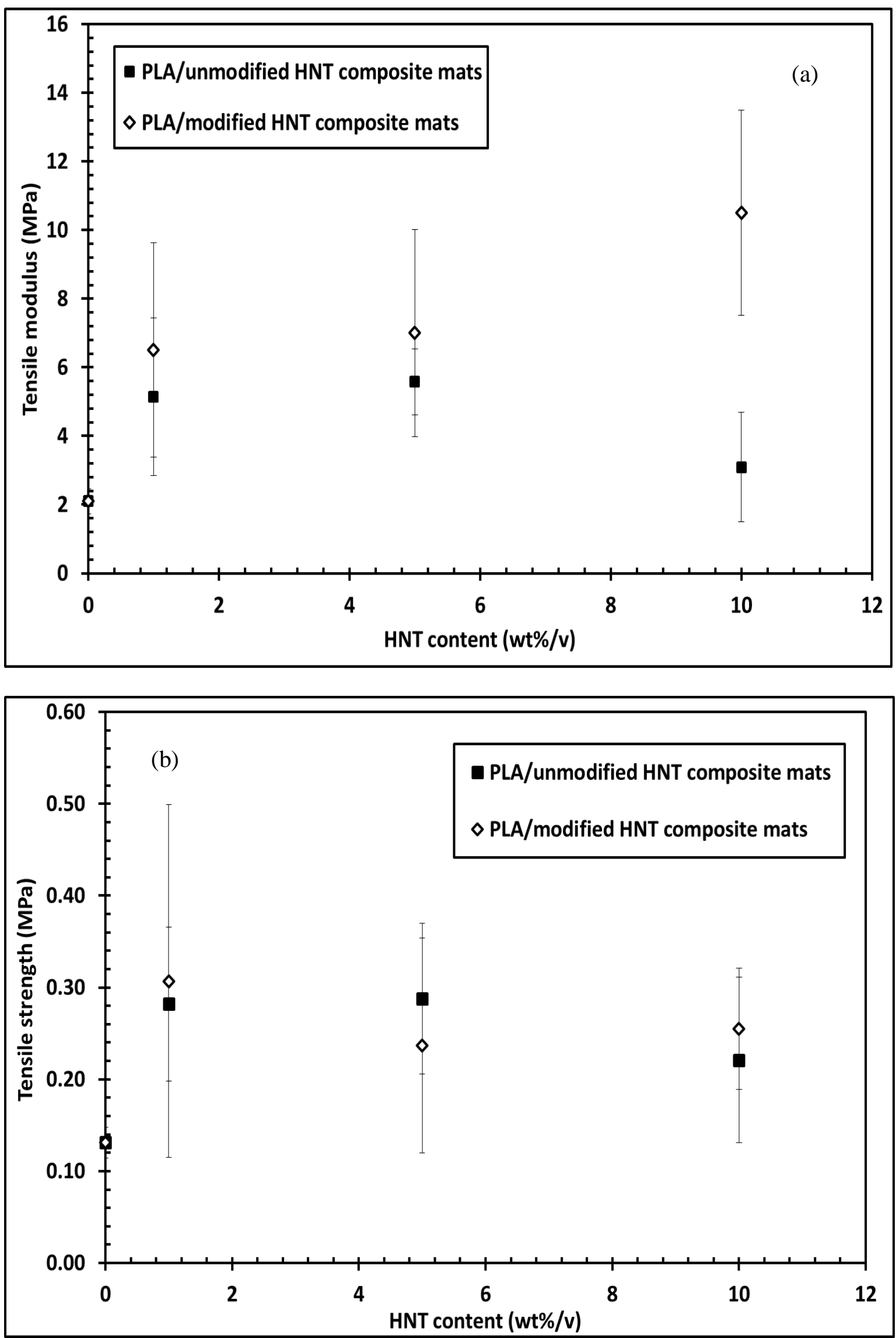

Fig. 5. 


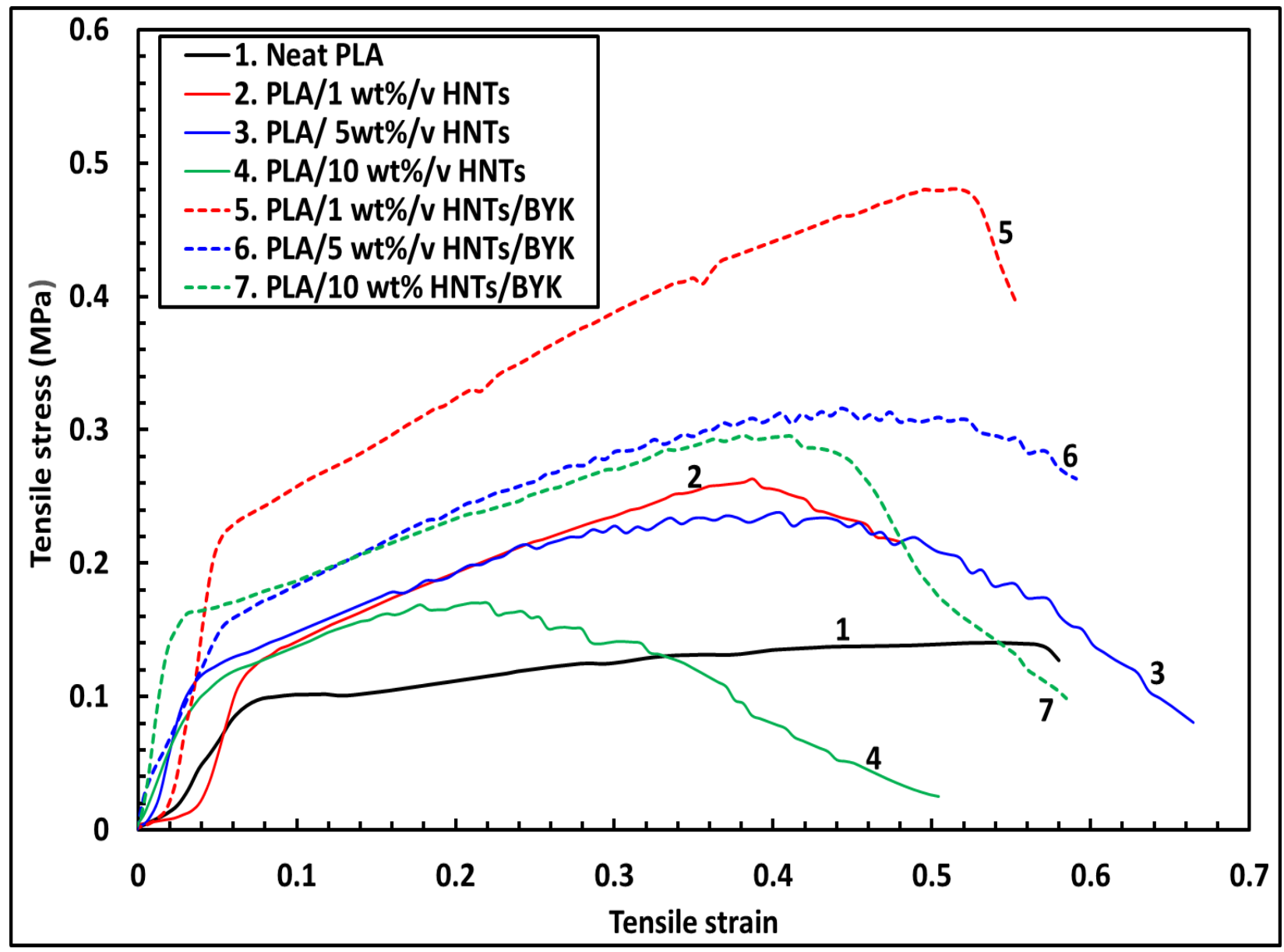

Fig. 6.

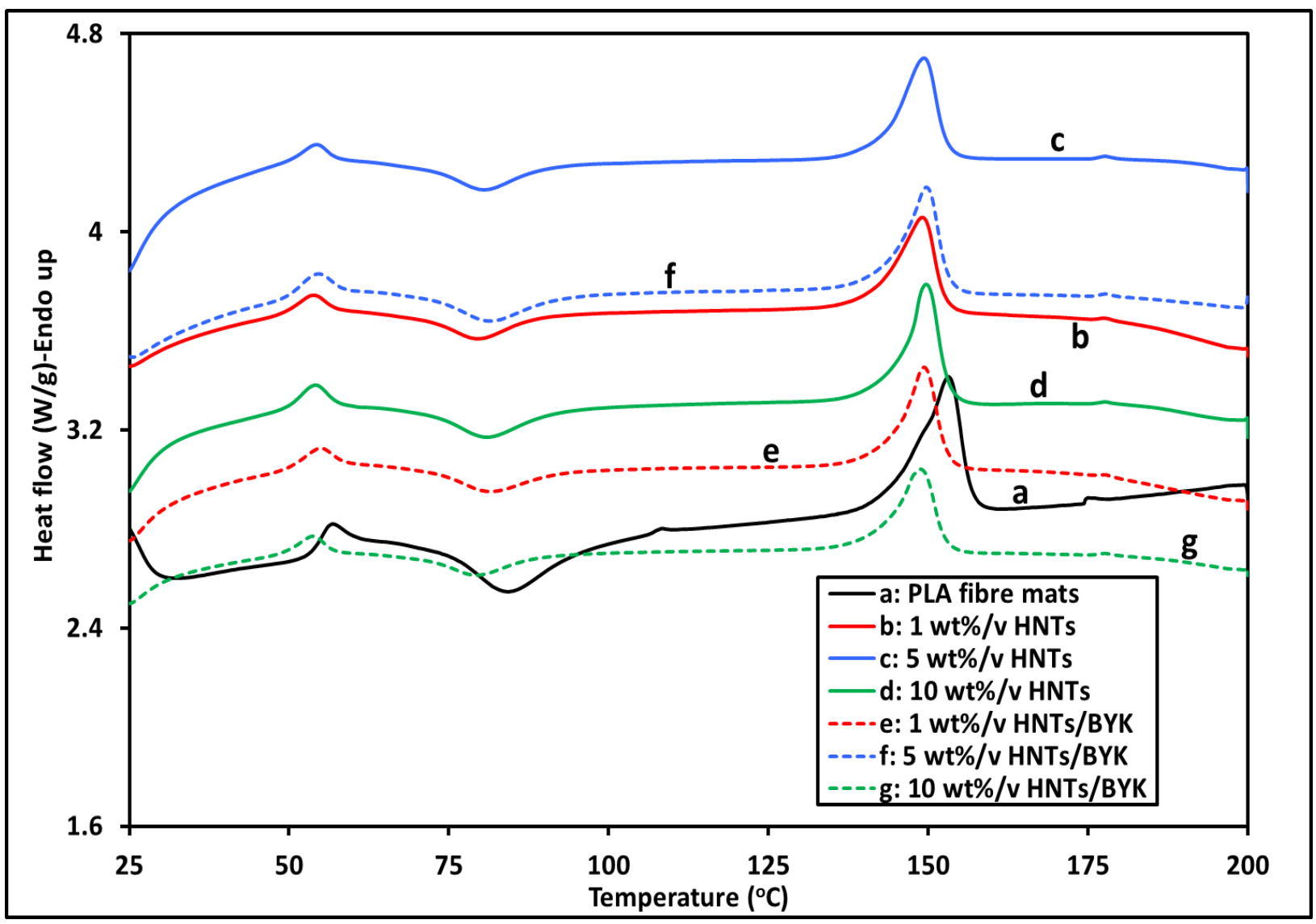

Fig. 7. 

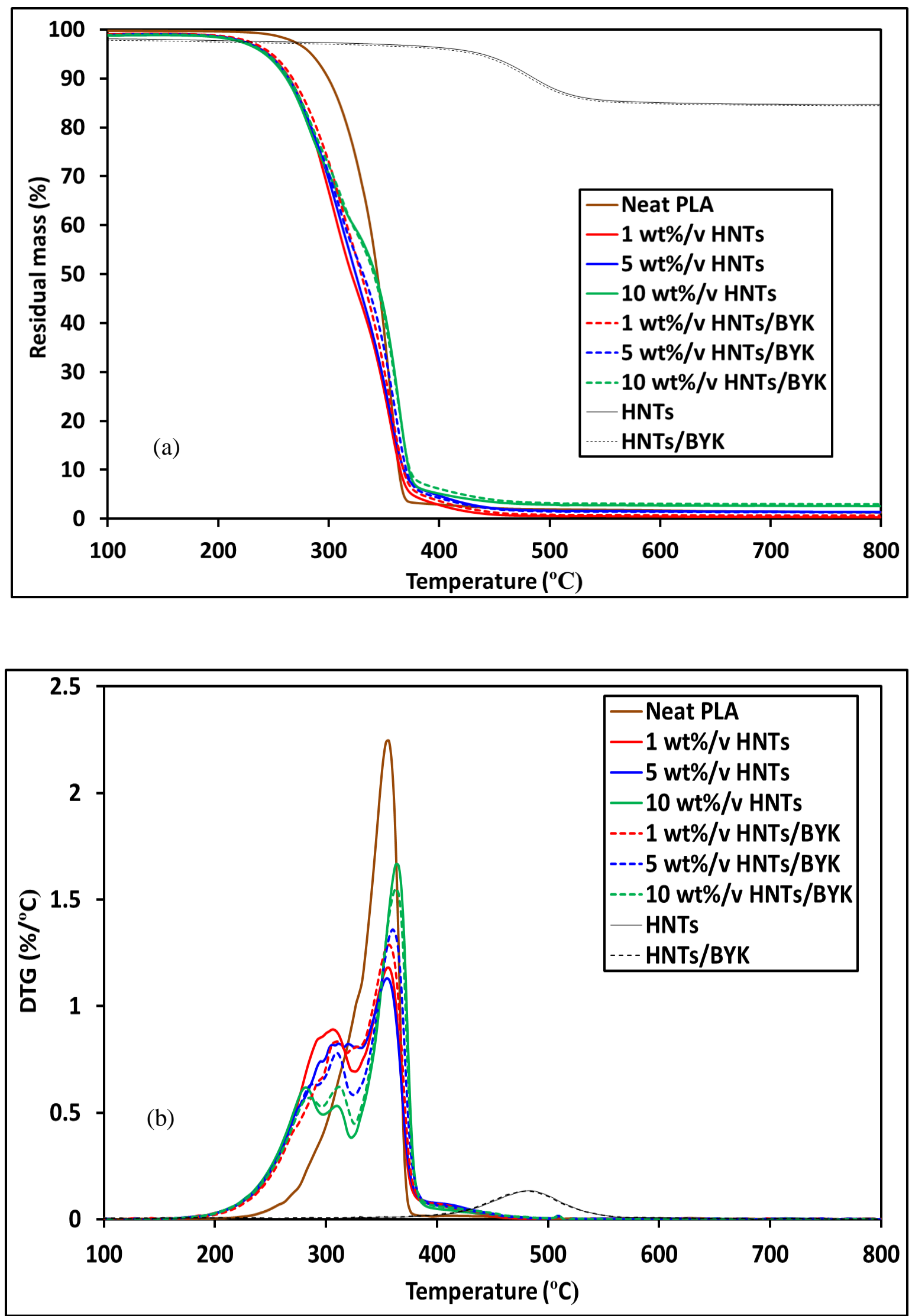

Fig. 8. 


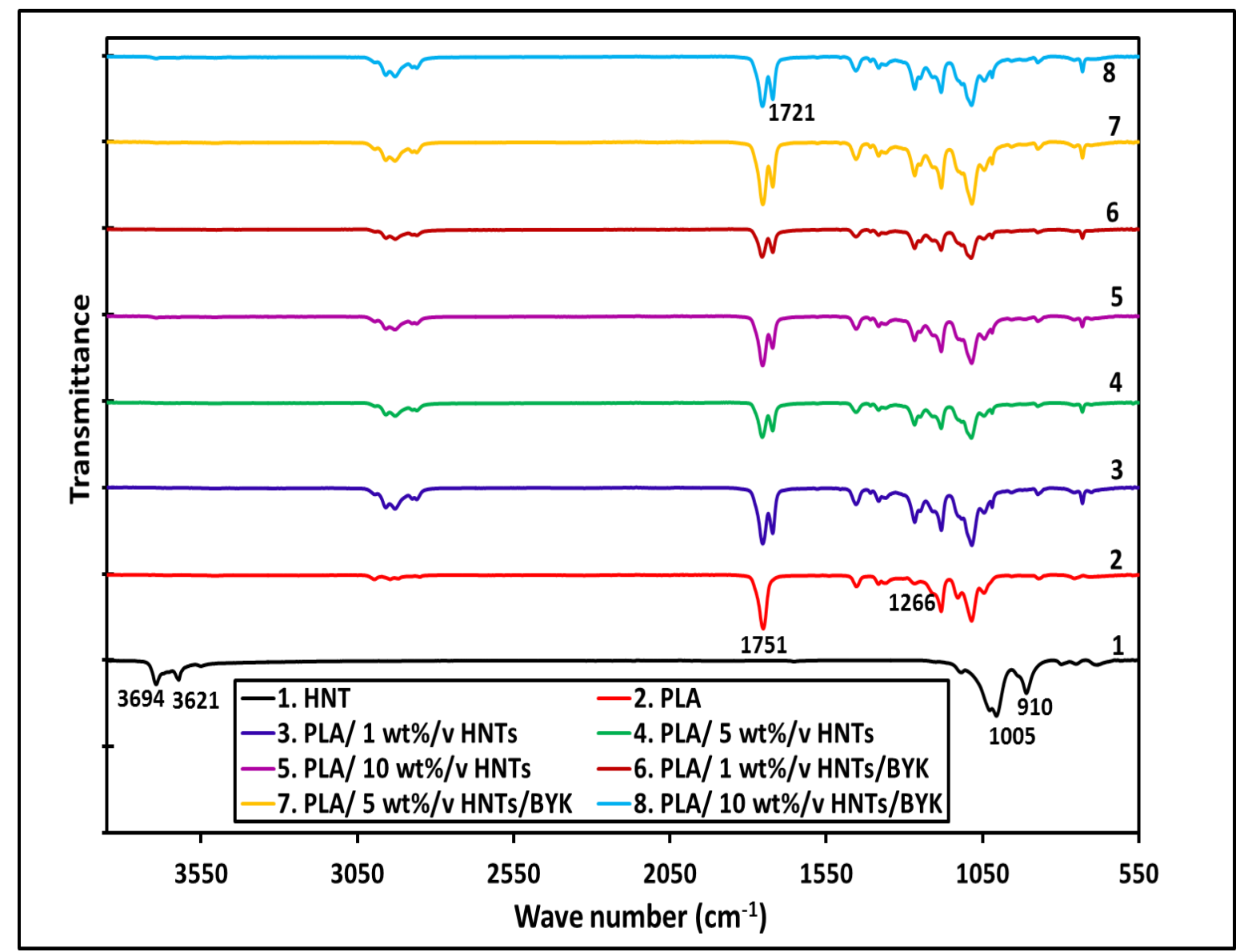

Fig. 9.

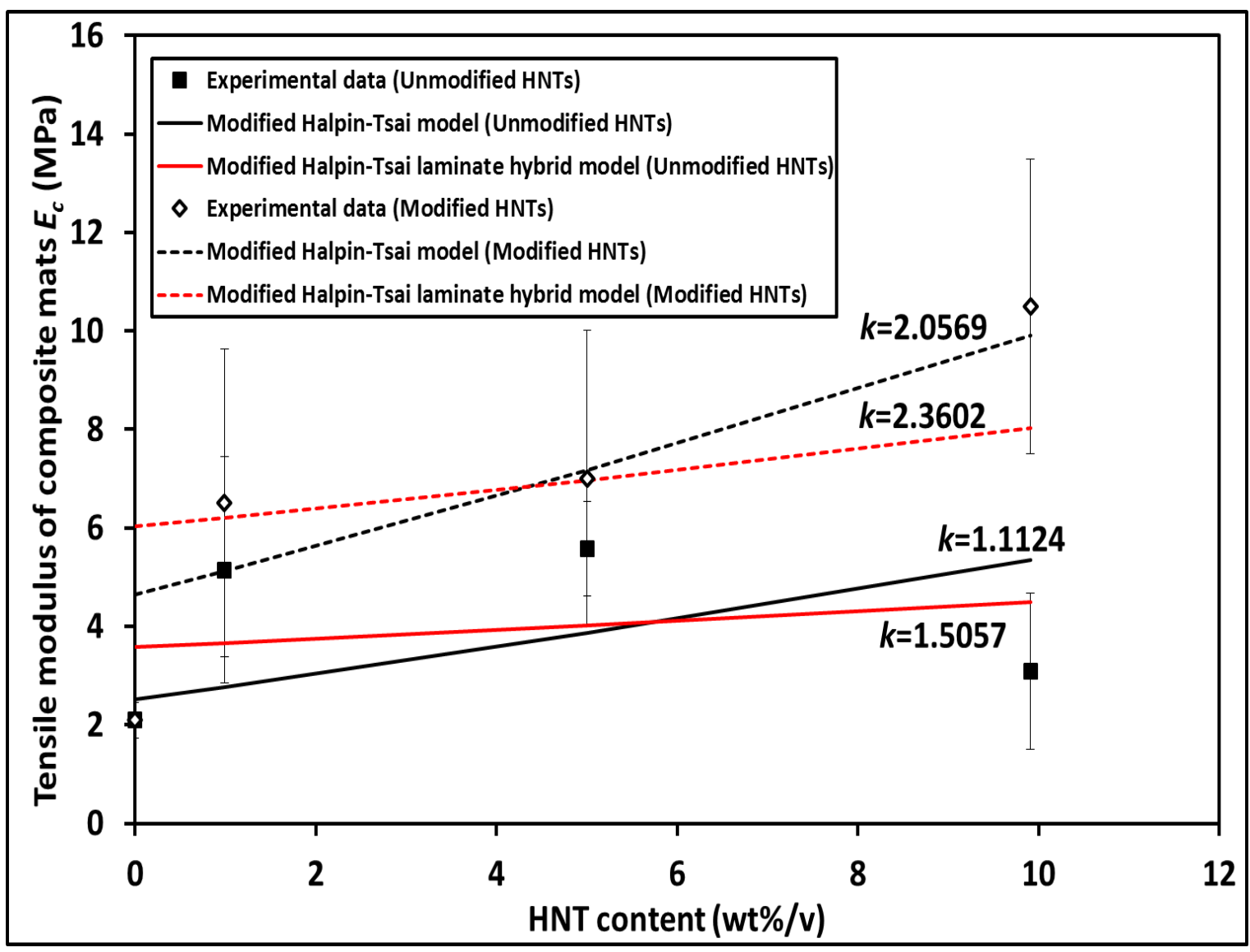

Fig. 10. 
Table 1 Mathematical modelling parameters used for PLA/HNT composite mats

\begin{tabular}{ccc}
\hline Modelling parameter & Used value & Reference \\
\hline$E_{f}(\mathrm{GPa})$ & 140 & {$[39]$} \\
$E_{m}(\mathrm{MPa})$ & 2.259 & Our experimental data \\
$L(\mathrm{~nm})$ & $2000 *$ & {$[15]$} \\
$d(\mathrm{~nm})$ & $200 * *$ & {$[15]$} \\
$\rho_{f}\left(\mathrm{~kg} / \mathrm{m}^{3}\right)$ & 2550 & Material data sheet \\
$\rho_{m}\left(\mathrm{~kg} / \mathrm{m}^{3}\right)$ & 1250 & Material data sheet
\end{tabular}

* Average value chosen based on the length range of HNTs from 1000 to $3000 \mathrm{~nm}$ [15].

**Average value chosen based on the diameter range of HNTs from 100 to $300 \mathrm{~nm}$ [15].

Table 2 DSC thermal properties of PLA mats and PLA/HNT composite mats
Material sample
$T_{g}\left({ }^{\circ} \mathrm{C}\right) \quad T_{c c}\left({ }^{\circ} \mathrm{C}\right)$
$T_{m}\left({ }^{\circ} \mathrm{C}\right)$
$\Delta H_{m}(\mathrm{~J} / \mathrm{g}) \quad \Delta H$
$\Delta H_{c c}(\mathrm{~J} / \mathrm{g}) \quad X_{c}(\%)$

$\begin{array}{ccccccc}\text { PLA } & 54.87 & 84.27 & 153.15 & 24.90 & 12.67 & 13.15 \\ \text { PLA/1 wt\%/v HNT composites } & 50.75 & 79.43 & 149.04 & 15.77 & 4.52 & 12.22 \\ \text { PLA/5 wt\%/v HNT composites } & 51.77 & 80.41 & 149.35 & 15.03 & 3.22 & 13.37 \\ \text { PLA/10 wt\%/v HNT composites } & 51.62 & 80.75 & 149.66 & 17.64 & 6.46 & 13.36 \\ & & & & & & \\ & & & & & & \\ \\ \begin{array}{c}\text { PLA/1 wt\%/v HNTs/BYK } \\ \text { composites }\end{array}\end{array}$


PLA/5 wt\%/v HNTs/BYK

composites

PLA/10 wt $\% / v$ HNTs/BYK

$\begin{array}{lll}51.45 & 79.43 \quad 148.86\end{array}$

14.33

3.12

13.39

composites

Table 3 TGA data for PLA mats, PLA/HNT composite mats, as-received HNTs and HNTs/BYK

\begin{tabular}{|c|c|c|c|c|c|c|}
\hline Material type & $\begin{array}{l}T_{5} \% \\
\left({ }^{\circ} \mathrm{C}\right)\end{array}$ & $\begin{array}{l}T_{50 \%} \\
\left({ }^{\circ} \mathrm{C}\right)\end{array}$ & $\begin{array}{l}T 95 \% \\
\left({ }^{\circ} \mathrm{C}\right)\end{array}$ & $\begin{array}{l}T_{d 1} \\
\left({ }^{\circ} \mathrm{C}\right)\end{array}$ & $\begin{array}{l}T_{d 2} \\
\left({ }^{\circ} \mathrm{C}\right)\end{array}$ & $\begin{array}{l}T_{d 3} \\
\left({ }^{\circ} \mathrm{C}\right)\end{array}$ \\
\hline PLA & 284.26 & 344.00 & 369.97 & & & 354.05 \\
\hline $\begin{array}{l}\mathrm{PLA} / 1 \mathrm{wt} \% / \mathrm{v} \mathrm{HNT} \\
\text { composites }\end{array}$ & 245.37 & 320.65 & 376.56 & 291.79 & 308.27 & 357.36 \\
\hline $\begin{array}{l}\text { PLA } / 5 \text { wt } \% / v \text { HNT } \\
\text { composites }\end{array}$ & 244.59 & 324.40 & 394.92 & 294.53 & 305.55 & 354.68 \\
\hline $\begin{array}{c}\mathrm{PLA} / 10 \mathrm{wt} \% / \mathrm{v} \mathrm{HNT} \\
\text { composites }\end{array}$ & 242.19 & 342.10 & 402.86 & 280.81 & 311.10 & 362.59 \\
\hline $\begin{array}{c}\text { PLA/1 wt } \% / \mathrm{v} \text { HNTs/BYK } \\
\text { composites }\end{array}$ & 248.67 & 329.27 & 383.16 & 291.72 & 305.46 & 357.20 \\
\hline $\begin{array}{c}\text { PLA/5 wt\%/v HNTs/BYK } \\
\text { composites }\end{array}$ & 243.89 & 331.03 & 388.99 & 283.61 & 308.42 & 360.17 \\
\hline $\begin{array}{c}\text { PLA/10 wt } \% / v \text { HNTs/BYK } \\
\text { composites }\end{array}$ & 244.09 & 340.69 & 420.79 & 280.91 & 311.22 & 362.73 \\
\hline HNTs & 437.31 & & & & & 482.84 \\
\hline HNTs/BYK & 431.94 & & & & & 480.20 \\
\hline
\end{tabular}

